\title{
Belowground Plant-Herbivore Interactions Vary among Climate-Driven Range-Expanding Plant Species with Different Degrees of Novel Chemistry
}

\author{
Rutger A. Wilschut ${ }^{1,2 \star t}$, Julio C. P. Silva ${ }^{1 \dagger}$, Paolina Garbeva ${ }^{3}$ and Wim H. van der Putten ${ }^{1,2}$ \\ ${ }^{1}$ Department of Terrestrial Ecology, Netherlands Institute of Ecology, Wageningen, Netherlands, ${ }^{2}$ Laboratory of Nematology, \\ Wageningen University and Research, Wageningen, Netherlands, ${ }^{3}$ Department of Microbial Ecology, Netherlands Institute of \\ Ecology, Wageningen, Netherlands
}

OPEN ACCESS

Edited by:

Philip G. Hahn

University of Montana, United States

Reviewed by:

lan Pearse,

United States Geological Survey,

United States

Eduardo de la Peña,

Consejo Superior de Investigaciones

Cientificas (CSIC), Spain

*Correspondence:

Rutger A. Wilschut

r.wilschut@nioo.knaw.nl

${ }^{\dagger}$ These authors have contributed equally to this work.

Specialty section:

This article was submitted to Plant Microbe Interactions,

a section of the journal

Frontiers in Plant Science

Received: 12 July 2017 Accepted: 11 October 2017 Published: 25 October 2017

Citation:

Wilschut RA, Silva JCP, Garbeva $P$ and van der Putten WH (2017) Belowground Plant-Herbivore Interactions Vary among Climate-Driven Range-Expanding Plant Species with Different Degrees of Novel Chemistry.

Front. Plant Sci. 8:1861. doi: 10.3389/fpls.2017.01861
An increasing number of studies report plant range expansions to higher latitudes and altitudes in response to global warming. However, consequences for interactions with other species in the novel ranges are poorly understood. Here, we examine how rangeexpanding plant species interact with root-feeding nematodes from the new range. Root-feeding nematodes are ubiquitous belowground herbivores that may impact the structure and composition of natural vegetation. Because of their ecological novelty, we hypothesized that range-expanding plant species will be less suitable hosts for rootfeeding nematodes than native congeneric plant species. In greenhouse and lab trials we compared nematode preference and performance of two root-feeding nematode species between range-expanding plant species and their congeneric natives. In order to understand differences in nematode preferences, we compared root volatile profiles of all range-expanders and congeneric natives. Nematode preferences and performances differed substantially among the pairs of range-expanders and natives. The range-expander that had the most unique volatile profile compared to its related native was unattractive and a poor host for nematodes. Other range-expanding plant species that differed less in root chemistry from native congeners, also differed less in nematode attraction and performance. We conclude that the three climate-driven rangeexpanding plant species studied varied considerably in their chemical novelty compared to their congeneric natives, and therefore affected native root-feeding nematodes in species-specific ways. Our data suggest that through variation in chemical novelty, range-expanding plant species may vary in their impacts on belowground herbivores in the new range.

\footnotetext{
Keywords: range-expanding plant species, novel weapons, plant-herbivore interactions, root chemistry, rootfeeding nematodes, volatile organic compounds, Centaurea stoebe
}

\section{INTRODUCTION}

One of the most evident ecological consequences of current climate change is the latitudinal and altitudinal range expansion of many plant and animal species (Walther et al., 2002; Parmesan, 2006; Le Roux and Mcgeoch, 2008). As not all species expand their range at similar rates (Berg et al., 2010), coevolved interactions between plants, aboveground and belowground organisms are likely 
to become disrupted, whereas novel interactions can be developed in the new range (Lavergne et al., 2010; Van Der Putten, 2012). Range-expanding plant species might benefit from these new biotic conditions when they do not encounter coevolved natural enemies in the expanded range (De Frenne et al., 2014; Dostálek et al., 2015). At the same time, rangeexpanders will become exposed to non-coevolved natural enemies that are native to these new areas. The strength of the enemy release effect will be largely determined by the inability of the novel natural enemies to exploit the range-expanders and the ability of the range-expanders to successfully defend themselves (Verhoeven et al., 2009). The present study was initiated in order to examine how root herbivores in the new range respond to range-expanding plant species.

Range-expanding plant species could benefit from the lack of coevolved novel natural enemies when they produce chemicals to which these enemies are not adapted. Such novel chemicals make the plants either less attractive or less digestible. For intercontinental introductions of exotic plant species, this possibility has been investigated under the "novel weapon hypothesis" (Callaway and Ridenour, 2004; Schaffner et al., 2011). Several studies have shown that invasive exotic plant species produce more unique shoot compounds than native plant species in the invaded range (Cappuccino and Arnason, 2006; Macel et al., 2014), thereby negatively affecting the performance of native aboveground invertebrate herbivores (Macel et al., 2014). The strength of novel weapon effects could differ between introduced exotic plant species and intra-continental rangeexpanders as more natural enemies may be shared between the original range and the new range of intra-continental rangeexpanders than of intercontinentally introduced exotic species. Yet, aboveground herbivores that lack a co-evolutionary history with both the range-expanding and the related native plant species performed less well on some successful range-expanders than on related natives (Engelkes et al., 2008). This suggests a role for plant chemistry in the success of range-expanding plants. However, the novel weapon hypothesis so far has not been tested in studies on intracontinental range-expanding plant species. Moreover, there is a paucity of studies testing the effects of novel chemistry on belowground herbivores, both for introduced exotics and intra-continental range-expanders.

In their new range, successful range-expanding plant species on average are less negatively affected by soil communities than congeneric natives (Van Grunsven et al., 2007; Engelkes et al., 2008). This effect has been explained by the on average lower accumulation of soil-borne fungal pathogens (Morriën and Van Der Putten, 2013) and root-feeding nematodes (Morriën et al., 2012) on the roots of range-expanding plant species than on congeneric natives. However, there is considerable variation in the outcome of plant-nematode interactions among rangeexpanding plant species (Morriën et al., 2012; Viketoft and Van Der Putten, 2014; Wilschut et al., 2016). A likely explanation for this variation that has not yet been studied is the role of novel plant chemistry. Therefore, the aim of the present study was to examine how differences in plant-nematode interactions between range-expanding and native plant species relate to differences in root chemistries. We compared preference and reproductive performance of root herbivores on range-expanders with congeneric plant species that are native in the new range, in order to confound our tests as minimal as possible with general differences in plant chemistry.

We tested the hypotheses that native generalist root-feeding nematodes (1) are more strongly attracted to native than to rangeexpanding plant species, (2) prefer native plant species over range-expanding plant species and (3) show higher reproduction on native than on range-expanding plant species. We studied differences in nematode attraction to single plants of all tested plant species (hypothesis 1), differences in nematode preference between range-expanders and related natives (hypothesis 2) and differences in nematode performance between range-expanders and related natives (hypothesis 3 ) under both lab and greenhouse conditions. As root volatiles are known to influence attraction of entomopathogenic nematodes (Rolfe et al., 2000; Rasmann et al., 2005; Turlings et al., 2012), we examined volatile profiles of all six plant species as they also may explain patterns in rootfeeding nematode attraction and preference. Together, our results will contribute to the understanding of how novel chemistry might affect belowground plant-herbivore interactions of rangeexpanding plant species.

\section{MATERIALS AND METHODS}

\section{Plant Species and Seed Collections}

We selected three plant species that recently expanded their range naturally from lower latitude areas to higher latitude areas in North-Western Europe and that have a related native species in their new range. Range-expanding plant species that were examined in the experiments were Centaurea stoebe L., Geranium pyrenaicum Burm. f., and Rorippa austriaca Crantz and their congeneric native species were C. jacea L., G. molle L., and R. sylvestris (L.) Besser. All six plant species now co-occur in riparian grassland areas in the eastern part of the RhineWaal area in The Netherlands. Therefore, these plant species are subjected to at least partly overlapping abiotic and biotic conditions. Range-expanding $R$. austriaca and G. pyrenaicum naturally established in the Netherlands at the end of the 19th century and are now widespread, while the first population of range-expanding $C$. stoebe in the Netherlands was recorded in the last decade of the 20th century (Floron, 2017). Seeds of all six plant species originate from natural areas in the Netherlands. Seeds of C. stoebe, G. molle, R. austriaca, and R. sylvestris were directly collected from single populations the field. Seeds of C. jacea were collected from mother plants that were grown in an outside experiment at NIOO-KNAW (Wageningen, The Netherlands) from seeds collected in a natural population. Seeds of G. pyrenaicum were delivered by the company Cruydthoeck (Nijeberkoop, Netherlands), that grows wild plants under field conditions from seeds that originate from natural field sites. For all experiments, seeds of Centaurea and Geranium species were surface-sterilized by washing for $3 \mathrm{~min}$ in a $10 \%$ bleach solution, followed by rinsing with demineralized water, after which they were germinated on glass beads. Due to their small size, seeds of both Rorippa species were not surface-sterilized, but directly 
germinated on sterilized soil. Seeds were germinated in a climate cabinet at $20 / 10^{\circ} \mathrm{C}$ and $16 \mathrm{~h} \mathrm{light} / 8 \mathrm{~h}$ darkness.

\section{Nematodes}

We used cultures of two root-feeding nematode species, the ectoparasitic Helicotylenchus pseudorobustus Steiner (hereafter Helicotylenchus) and the sedentary endoparasitic Meloidogyne hapla Chitwood (hereafter Meloidogyne), originating from populations in The Netherlands. We selected these species as they both have a wide host range, are common and widely distributed throughout Europe (Bongers, 1988). Both used cultures were previously established in a greenhouse at NIOO-KNAW. The culture of Helicotylenchus on Marram grass (Ammophila arenaria L.) originates from nematodes collected from coastal dunes. The culture of Meloidogyne originates from nematodes collected from a field near Bovensmilde (Drenthe, Netherlands) which were subsequently cultured on tomato (Solanum lycopersicum L.).

\section{Nematode Choice Experiments}

To study differences in nematode attraction and preference, we performed choice experiments on agar and in soil, where nematodes could move to one of two opposing treatments. To examine nematode attraction to a plant species, we planted one seedling of a species at one side and left the other side unplanted. To examine nematode preference for either natives or range-expanders we planted single seedlings of congeneric native and range-expanding plant species at opposing sides of the test units. As a control for attraction and preference, we examined nematode movement in test units without seedlings. We calculated the percentage of nematodes moving to either one of the sides of the test units.

\section{Choice Experiment on Agar}

To examine nematode choice in vitro, we used Petri dishes of $9 \mathrm{~cm}$ diameter filled with $20 \mathrm{ml}$ 0.5\% microbial agar (Merck kGaA, Germany) (Piskiewicz et al., 2009). We used eight independent replicates for each treatment. We placed 20-daysold seedlings $4 \mathrm{~cm}$ from the center of the Petri dish. Thereafter, the Petri dishes were placed in a climatized chamber at $16 / 8 \mathrm{~h}$ light/dark and $20^{\circ} \mathrm{C}$. After 2 days, $20 \mu \mathrm{l}$ of tap water suspension containing 40 juveniles of either Helicotylenchus or Meloidogyne was pipetted at the center of the Petri dishes. Nematode choice was examined 2 days after inoculation by counting using a stereomicroscope (200× magnification). We considered a nematode to be significantly attracted to one treatment when it moved at least $0.5 \mathrm{~cm}$ into the half of the Petri dish oriented toward that treatment.

\section{Choice Experiment in Soil}

To examine nematode choices under more natural conditions than on agar, we performed a choice experiment in soil-filled Y-tubes (Van Tol et al., 2001; Piskiewicz et al., 2009) in a greenhouse at $16 / 8 \mathrm{~h}$ light/dark and $20 / 15^{\circ} \mathrm{C}$. We used six independent replicates for each treatment. Each Y-tube consisted of a core piece and two removable arms (see Supplementary Figure 1A), which were all filled with gamma-sterilized soil (25 KGray, Syngenta bv, Ede, Netherlands). The soil originated from a former agricultural field (Beneden-Leeuwen, Netherlands; $\mathrm{N} 51^{\circ}$ 53.952, $\mathrm{E} 05^{\circ} 33.670$ ) in a riparian system where all plant species can occur. Prior to sterilization, the field soil was homogenized with sand at a rate of 2:1 (w:w) in order to reduce the relative clay content. Seedlings of 20 days old were planted in the Y-tube arms. Soil moisture was adjusted to $10 \%(\mathrm{w}: \mathrm{w})$ and maintained at this level until nematode inoculation. Five days after planting the seedlings, $2 \mathrm{ml}$ of water suspension with 200 Helicotylenchus or Meloidogyne juveniles was inoculated $2 \mathrm{~cm}$ deep in both sides of the core piece, to have an equal distribution of nematodes throughout the core piece. Then, both units with the planted seedlings were placed on the Y-tube and for the remaining experimental time the arms were moistened daily with $5 \mathrm{ml}$ of demineralized water. After that, nematodes could enter an arm in which the roots were growing. Four days after inoculation, the two arms of the Y-tube were separated and nematodes from each arm and the core piece were extracted by Cobb's decantation (Cobb, 1918) and counted using an inverted light microscope (200x magnification).

\section{Nematode Reproduction Experiment}

For each plant species, ten 12-days-old seedlings were planted separately in $11 \mathrm{~cm} \times 11 \mathrm{~cm} \times 12 \mathrm{~cm}$ pots filled with soil homogenized and sterilized as explained above. The pots were placed in a greenhouse in a randomized block design with five replicate blocks. After 12 days, pots were inoculated with $2 \mathrm{ml}$ water suspension with either 200 Meloidogyne or 200 Helicotylenchus juveniles. During the subsequent 16 weeks the pots were watered twice a week and kept on the same weight of approximately $870 \mathrm{~g}$, of approximately 15\% (w:w) soil moisture content. Thereafter, roots and soils were separated and used for nematode extraction. All roots were washed in $200 \mathrm{ml}$ tap water, after which the washing water containing nematodes that were present in the rhizosphere was stored. Nematodes of each individual replicate were combined into a single sample by extracting all nematodes from the wash and soil using an Oostenbrink elutriator (Oostenbrink, 1960). Roots collected from pots inoculated with the ectoparasite Helicotylenchus were dried at $70^{\circ} \mathrm{C}$. Roots from pots inoculated with Meloidogyne were split and both halves were weighed fresh. One half of the roots was dried at $70^{\circ} \mathrm{C}$ until constant weight, whereas the other half was cut into pieces of 1$2 \mathrm{~cm}$ and placed for 4 weeks in a mistifier to extract nematodes from the inside of the roots (Funnel-spray method; Oostenbrink, 1960). Total dry root biomass was assessed using total fresh root weight and fresh/dry weight ratio of each sample. Nematode suspensions were harvested from the mistifier after 2 and 4 weeks, combined, and concentrated to $10 \mathrm{ml}$. Nematodes were counted using an inverted light microscope $(200 \times$ magnification).

\section{Root Volatile Analysis}

To relate nematode attraction, preference, and performance to root chemistry, we analyzed root volatile profiles by Gas Chromatography Quadrupole Time of Flight (GC-QTOF) analysis. 


\section{Volatile Trapping}

Four 20-days-old seedlings of each plant species were placed in individual $70 \mathrm{ml}$ glass pots filled with sterilized soil (see choice experiment in soil). After 15 days, steel traps containing the volatile absorbants Tenax TA (150 mg) and Carbopack B (150 mg; Markes International Ltd., Llantrisant, United Kingdom) were attached at both sides of the glass pots (Supplementary Figure $1 \mathrm{~B}$ ). After $24 \mathrm{~h}$ of incubation the traps were removed, capped and stored at $4^{\circ} \mathrm{C}$ until GC-QTOF analysis.

\section{GC-QTOF Analysis of Volatiles Compounds}

The volatiles were collected from the traps using an automated thermos desorption unit (Unity TD-100, Markes International Ltd., Llantrisant, United Kingdom) at $210^{\circ} \mathrm{C}$ for $12 \mathrm{~min}$ (Helium flow $50 \mathrm{ml} / \mathrm{min}$ ) and trapped on a cold trap at $-10^{\circ} \mathrm{C}$. The volatiles were introduced into the GC-QTOF (model Agilent 7890B GC and the Agilent 7200A QTOF, Santa Clara, CA, United States) by heating the cold trap for $3 \mathrm{~min}$ to $280^{\circ} \mathrm{C}$. Split ratio was set to $1: 10$, and the column used was a $30 \mathrm{~mm} \times 0.25 \mathrm{~mm}$ ID RXI-5MS, film thickness $0.25 \mu \mathrm{m}$ (Restek 13424-6850, Bellefonte, PA, United States). The following temperature program was used: $39^{\circ} \mathrm{C}$ for $2 \mathrm{~min}$, from 39 to $95^{\circ} \mathrm{C}$ at $3.5^{\circ} \mathrm{C} / \mathrm{min}$, then to $165^{\circ} \mathrm{C}$ at $6^{\circ} \mathrm{C} / \mathrm{min}$, to $250^{\circ} \mathrm{C}$ at $15^{\circ} \mathrm{C} / \mathrm{min}$ and finally to $300^{\circ} \mathrm{C}$ at $40^{\circ} \mathrm{C} / \mathrm{min}$ and $20 \mathrm{~min}$ at $300^{\circ} \mathrm{C}$. The volatiles were detected by a mass spectrometer (MS) operating at $70 \mathrm{eV}$ in EI mode. Mass spectra were acquired in full-scan mode (30-400AMU, 4 scans/s). GC-MSdata were collected and converted to a mzData file using the Chemstation B.06.00 (Agilent Technologies, United States). Data were further processed with MZmine 2.14.2 (Pluskal et al., 2010) with the tools mass detection (centroid mode, noise level $=1000$ ), chromatogram builder ( $\min$ time span $=0.05 \mathrm{~min}$, min height $=1.5 \mathrm{E} 03, \mathrm{~m} / \mathrm{z}$ tolerance of $1 \mathrm{~m} / \mathrm{z}$ or $5 \mathrm{ppm})$, and chromatogram deconvolution (local minimum search, chromatographic threshold $=40 \%$, Min in $\mathrm{RT}$ range $=0.1 \mathrm{~min}$, Min relative height $=2.0 \%$, Min absolute height $=1.5 \mathrm{E} 03$, Min ratio of peak top/edge $=2$, peak duration $=0.0-0.5 \mathrm{~min}$ ). Detected and deconvoluted peaks were identified by their mass spectra using NIST MS Search and NIST 2014 (National Institute of Standards and Technology, United States) and aligned using Random Sample Consensus (RANSAC) aligner ( $\mathrm{mz}$ tolerance $=1 \mathrm{~m} / \mathrm{z}$ or $5 \mathrm{ppm}$, RT tolerance $=0.1$, RT tolerance after correction $=0.05$, RANSAC iteration $=10000$, Min number of points $=60 \%$, threshold value $=0.1$ ). Processed data were exported for further statistical analysis as explained under 'Statistical analysis.' The identification of detected compounds was further evaluated using the software AMDIS 2.72 ${ }^{1}$ (Stein, 1999). The retention indexes were calculated for each compound and compared with those found in NIST 2014 and in-house databases.

\section{Statistical Analyses}

Differences in nematode attraction and preference were tested by pair-wise $t$-tests in SigmaPlot (Systat software, Inc.). Overall differences in nematode attraction between natives and rangeexpanders were tested using general linear models with origin as fixed factor and plant species as random factor (packages lme4 and lmerTest; Bates et al., 2014; Kuznetsova et al., 2015) using R studio (version 0.98.507; R Core Development Team, 2012). Differences in nematode numbers between plant species were tested for each nematode species separately using generalized linear models with a negative binomial error distribution (MASS package; Venables and Ripley, 2013) modeling fixed factors 'plant species' and 'experimental block'. Wald post hoc tests were then used to test for differences between plant species using the phia package (De Rosario-Martinez, 2013). Using Pearson correlation tests, we examined whether nematode reproduction corresponded with nematode attraction in the y-tubes. Analyses on volatile data were performed using MetaboAnalyst V3.0 $0^{2}$ (Xia et al., 2015). Prior to One-way ANOVA and multivariate analyses (PLS-DA) data were normalized via log-transformation and auto scaling. To identify mass features significantly differing between plant species, a one-way-ANOVA with post hoc Tukey HSD-tests was performed. Mass features were considered to be statistically relevant when $p$ - and FDR-values were $\leq 0.05$.

\section{RESULTS}

\section{Nematode Attraction}

First, we confirmed that the controls in the nematode attraction experiments were effective. Indeed, when the tests were performed in the absence of plants both on agar and in soil neither Helicotylenchus nor Meloidogyne showed significant movement away from the point of addition (Figure $\mathbf{1}$ and Supplementary Figure 2).

\section{Meloidogyne}

On average, there was a trend of stronger attraction of Meloidogyne to natives than to range-expanding plant species on agar (natives: $25.3 \pm 3.6 \%$, range-expanders: $10.9 \pm 3.9 \%$; $F=7.56, p=0.051$ ), but this was not significant in soil (natives: $21.9 \pm 4.4 \%$, range-expanders: $9.0 \pm 3.8 \% ; F=4.86, p=0.09$ ). On agar, all natives significantly attracted Meloidogyne away from the empty control (all $t$-values $>3.48$, all $p$-values $<0.05$; Supplementary Figure 2A), whereas none of the range-expanders did so (Supplementary Figure 2A). In soil, all three native species significantly attracted Meloidogyne away from the empty controls (all $t$-values $>6.65$, all $p$-values $<0.01$; Figure 1A). Both range-expanding Geranium and Rorippa also attracted Meloidogyne away from the empty control in soil ( $t$-values $>4.84$, $p$-values < 0.01; Figure 1A). Interestingly, the range-expanding Centaurea significantly repelled Meloidogyne toward the empty control in both agar and soil $(t$-values $<-3.21$, $p$-values $<0.05$; Figure 1A and Supplementary Figure 2A). Thus, all natives significantly attracted Meloidogyne, whereas range-expanders either repelled Meloidogyne or attracted Meloidogyne only in one of the two test units.

\footnotetext{
${ }^{1}$ http://chemdata.nist.gov/
} 

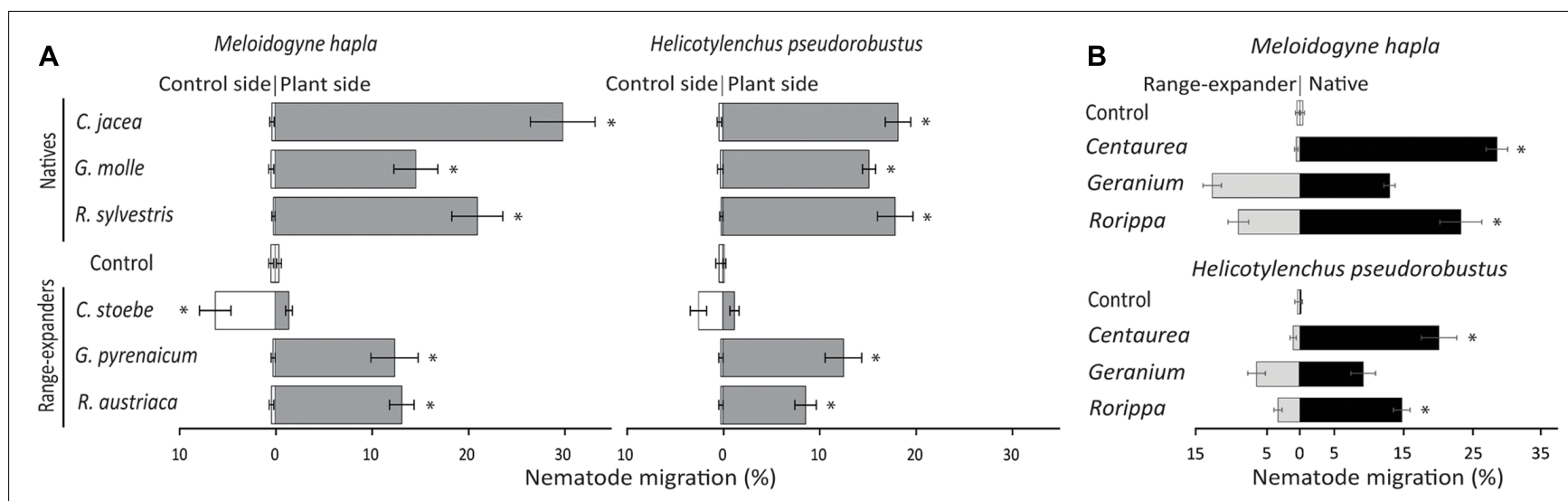

FIGURE 1 | (A) Attraction or repellence (\% individuals migrated) of the nematode species Meloidogyne hapla and Helicotylenchus pseudorobustus by native and range-expanding plant species in sterilized soil. (B) Nematode preference between native plant species Centaurea jacea, Geranium molle, and Rorippa sylvestris and congeneric range-expanders $C$. stoebe, G. pyrenaicum, and $R$. austriaca. In both panels horizontal bars show averages \pm standard errors and asterisks represent significant paired $t$-test values $(p<0.05)$ between empty control and plant $(\mathbf{A})$ or between native and range-expanding plant species $(\mathbf{B})$.

\section{Helicotylenchus}

On average, native plant species did not attract Helicotylenchus more strongly than range-expanders on agar (natives: $21.9 \pm 8.0 \%$, range-expanders: $13.6 \pm 2.4 \% ; F=0.99$, $p=0.38$ ), while they did so in soil (natives: $17.2 \pm 0.8 \%$, range-expanders: $7.4 \pm 3.3 \% ; F=7.83, p<0.05$ ). Individually, all native plant species significantly attracted Helicotylenchus in both test units, when compared to empty controls (all $t$-values $>3.2$, all $p$-values $<0.05$; Figure $\mathbf{1 A}$ and Supplementary Figure 2A). On agar only range-expanding Geranium significantly attracted Helicotylenchus away from the empty control $(t=4.34, p<0.01$; Supplementary Figure 2A), while in soil both range-expanding Geranium and Rorippa did so ( $t$-values $>6.57, p$-values $<0.01$; Figure 1A). Range-expanding Centaurea significantly repelled Helicotylenchus toward the empty control on agar $(t=-2.83, p<0.05$; Supplementary Figure 2A), but not in soil ( $t=-1.98, p=0.10$; Figure 1A). Overall, native plant species always significantly attracted Helicotylenchus, whereas attraction and repellence by rangeexpanding plant were species-specific and depended on test unit.

\section{Nematode Preference}

Meloidogyne and Helicotylenchus preferred native Centaurea and Rorippa over their congeneric range-expanders ( $t$-values $>3.68$, $p$-values $<0.05$; Figure 1B and Supplementary Figure 2B), although the preference of Helicotylenchus for native Rorippa was not significant on agar $(t=1.47, p=0.19)$. Both Meloidogyne and Helicotylenchus did not show a preference for either native or range-expanding Geranium on either agar or in soil (all $t$-values $<1.59$, all $p$-values $>0.15$; Figure $1 B$ and Supplementary Figure 2B). Therefore, our results show that two out of three native plant species were preferred over related range-expanding plant species by both nematode species, whereas in the third plant pair both nematode species did not show a preference for either the native or the rangeexpander.

\section{Nematode Reproductive Performance}

Meloidogyne reproduction differed significantly among plant species (explained deviance $=182.45, p<0.0001$ ). Meloidogyne numbers were higher on native $C$. jacea than on range-expanding C. stoebe $\left(\chi^{2}=251.94, p<0.0001\right.$; Figure 2$)$ and higher on native $R$. sylvestris than on range-expanding $R$. austriaca $\left(\chi^{2}=12.18\right.$, $p<0.001$; Figure 2). However, in Geranium, Meloidogyne numbers were higher on the range-expander $G$. pyrenaicum than on the native G. molle $\left(\chi^{2}=5.87, p<0.05\right.$; Figure 2$)$. Helicotylenchus numbers also differed significantly among plant species (explained deviance $=114.05, p<0.0001$; Figure 2). There were significantly more Helicotylenchus on native C. jacea than on range-expander $C$. stoebe $\left(\chi^{2}=10.10, p<0.05\right.$; Figure 2). However, post hoc analysis of the other two plant pairs did not reveal any significant differences in Helicotylenchus numbers between range-expanders and congeneric natives. Meloidogyne numbers per plant species strongly correlated with the attraction by these plant species in y-tubes $\left(R^{2}=0.92\right.$, $p<0.01$; Figure 3A), while this correlation was not significant for Helicotylenchus $\left(R^{2}=0.11, p=0.52\right.$; Figure 3B).

\section{Root Volatiles}

We detected 1964 putative volatile compounds in all samples, of which approximately 25\% (491 volatile compounds) were produced by plants (Supplementary Figure 3). The other 1473 volatile compounds were detected in the tubes containing only gamma-sterilized soil. When the root volatiles of all six plant species were analyzed together, the strongest overlap between species was found within the pairs of congeneric species, indicating that chemistry varies more strongly between genera than within genera (Supplementary Figure 4). Within the Centaurea pair 21 volatile compounds were significantly different between the native and range-expander, resulting in a clear separation of their volatile profiles (Figure 4A). Five of these compounds were detected only in the headspace of C. stoebe: indene, tridecane and nonadecane (alkanes), 


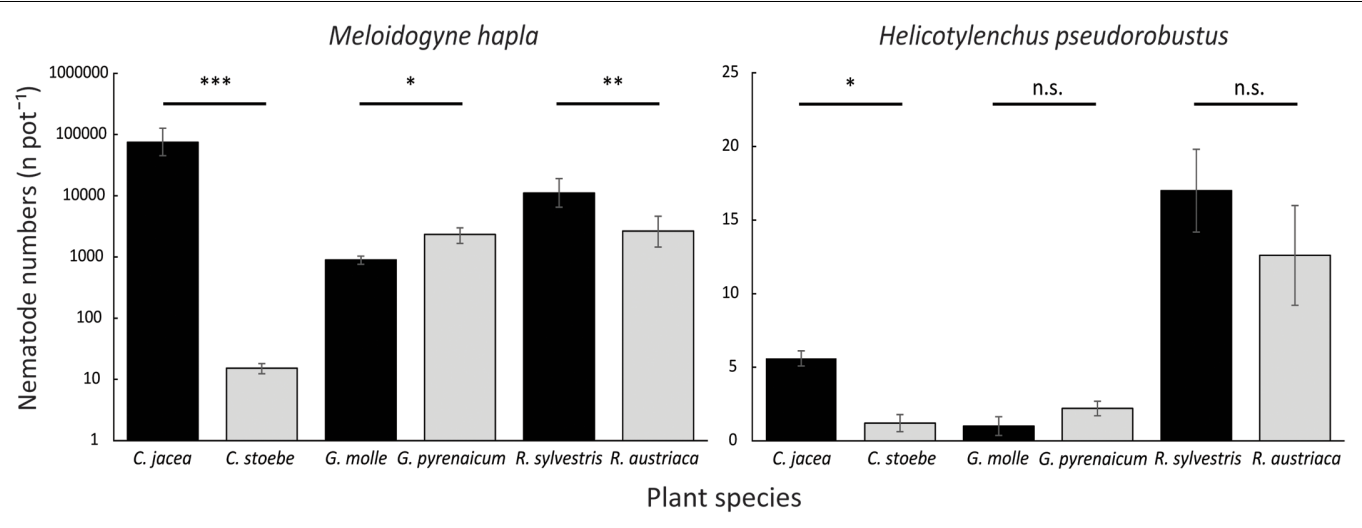

FIGURE 2 | Mean total numbers ( $\mathrm{N} \mathrm{pot}^{-1}$ ) of root-feeding nematodes $M$. hapla (left; logarithmic scale) and $H$. pseudorobustus (right; linear scale) on range-expanding plant species $C$. stoebe, G. pyrenaicum, and $R$. austriaca (gray), and congeneric natives $C$. jacea, G. molle, and $R$. sylvestris (black). Vertical bars show means \pm standard errors. Asterisks indicate levels of significance $\left({ }^{*} p<0.05,{ }^{* *} p<0.01,{ }^{* * *} p<0.001\right.$, n.s., not significant) of pairwise post hoc Wald tests within plant pairs.

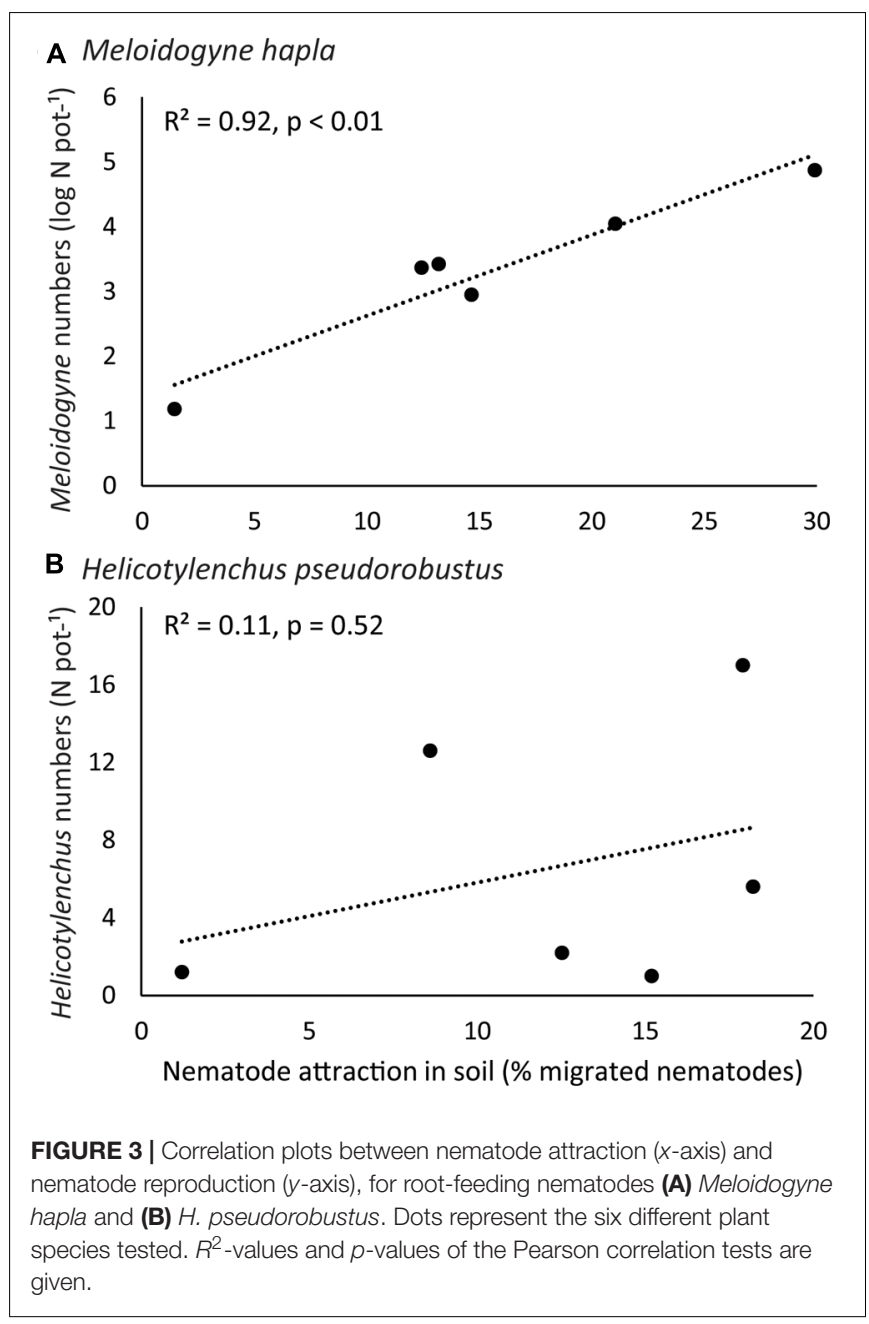

1,2-benzisothiazole (benzenoids/ketone) and alpha-gurjunene (sesquiterpene), and three volatiles were detected only in the headspace of the native C. jacea: petasitene (sesquiterpene), benzophenone (benzenoids/ketone), and an unknown terpene (Table 1). Thirteen compounds where found in both Centaurea species, but in different abundances (Table 1). Volatile profiles from native and range-expanding Geranium and Rorippa were less clearly separated in the PLS-DA score plots, although samples from controls, native and range-expanding plants could still be divided into three distinct groups with 95\% confidence intervals (Figures 4B,C). There were 11 volatiles that showed significant differences between the Geranium species and 6 between the Rorippa species (all p-values $<0.05$ ). Native G. molle produced five unique volatile compounds, compared to four by range-expanding $G$. pyrenaicum, while two volatiles differed in production levels between the species. The native $R$. sylvestris produced four unique compounds compared to two unique compounds that were produced exclusively by the rangeexpander R. austriaca. Therefore, differences in volatile profiles between range-expanders and congeneric natives depended on the species pair; in two out of three cases, the range-expander produced fewer unique volatiles than the congeneric native.

\section{DISCUSSION}

Several studies have proposed that invasiveness of intercontinentally introduced exotic plant species can be enhanced by their novel chemistry, e.g., through allelopathy (Callaway and Aschehoug, 2000; Zheng et al., 2015), or by the suppression of the local natural enemies (Schaffner et al., 2011). Yet, little is known about the effects of novel chemistry of intracontinental climate-driven range-expanders on communities in the new range. Moreover, empirical studies testing novel chemistry effects on belowground plant-herbivore interactions in the novel range are lacking. Here, we show that root-feeding nematodes from the novel range were strongly attracted to native plant species, while, in support of our hypothesis, the average attraction by range-expanders mostly was less strong. Yet, we also found substantial differences in nematode attraction among range-expanding plant species: while the range-expanding 

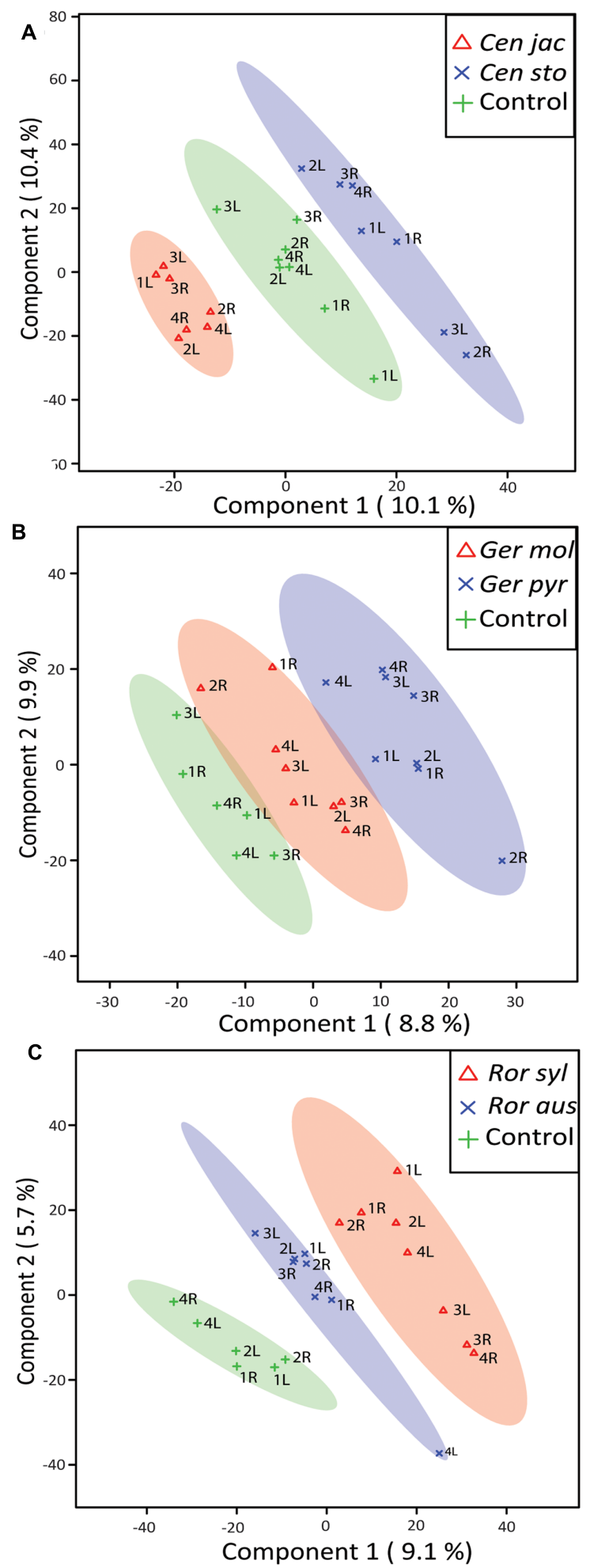

FIGURE 4 | Partial least square-discriminant analysis (PLS-DA) score plots of root volatile profiles measured with GC-QTOF-MS. The semi-transparent ovals outline the 95\% confidence intervals of natives (red triangles),

range-expanders (blue crosses) and sterilized control soils (green crosses) for Centaurea (A), Geranium (B), and Rorippa (C). Sample numbers and position of the volatile trap (left or right) are given.
C. stoebe repelled both nematode species in at least one of the attraction experiments, range-expanding G. pyrenaicum and $R$. austriaca attracted nematodes. Therefore, we show that some range-expanding plant species will attract considerable amounts of root-feeding nematodes in their new range, while other species will repel them, potentially leading to profound differences in herbivore pressure between range-expanders in their new range.

In test units with both natives and congeneric rangeexpanders, both nematode species preferred native Centaurea and Rorippa over their congeneric range-expanders, while our hypothesis of stronger nematode preference for natives was not confirmed when comparing the Geranium species. In plant communities in the new range, the preference for native plant species could lead to apparent competition (Holt, 1977), when natives experience stronger herbivore pressure (Orrock et al., 2008), leading to indirect competitive benefits for the range-expanders. For Meloidogyne, reproduction strongly corresponded with the attraction to the different plant species, as we found that Meloidogyne reproduction was significantly higher in the roots of native Centaurea and Rorippa than in the roots of their congeneric range-expanders. Notably, the differences in Meloidogyne reproduction between the Centaurea species were more substantial than between the Rorippa species. This was especially due to poor nematode reproduction on the range-expanding C. stoebe, which is in line with a previous study (Wilschut et al., 2016). Helicotylenchus numbers did not fully

TABLE 1 | Volatile organic compounds produced by native Centaurea jacea and range-expanding $C$. stoebe.

\begin{tabular}{llll}
\hline Compound name & RT & ELRI & Plant \\
\hline Sulfur dioxide & 2.04 & 488 & $\mathrm{CJ}$ \\
Dimethylsulfide & 2.4 & 529 & $\mathrm{CS}$ \\
Carbon disulfide & 2.5 & 541 & $\mathrm{CJ}$ \\
Furan, 2-methyl & 2.9 & 583 & $\mathrm{CJ}$ \\
1,3-dioxolane, 2-methyl- & 3.4 & 639 & $\mathrm{CS}$ \\
benzene 1,2 dimethyl & 10.1 & 890 & $\mathrm{CJ}$ \\
Dimethyl sulfone & 10.9 & 916 & $\mathrm{CS}$ \\
Dimethyl trisulfide & 13.1 & 963 & $\mathrm{CS}$ \\
Mesitylene & 14.3 & 990 & $\mathrm{CJ}$ \\
Indene** & 15.7 & 1023 & $\mathrm{CS}$ \\
Acetophenone & 17.4 & 1062 & $\mathrm{CS}$ \\
1,2-benzisothiazo** & 23.9 & 1229 & $\mathrm{CS}$ \\
Tridecane** & 26.8 & 1299 & $\mathrm{CS}$ \\
Petasitene* & 30.1 & 1398 & $\mathrm{CJ}$ \\
Alpha-gurjunene** & 30.4 & 1407 & $\mathrm{CS}$ \\
Unknown terpene* & 32.73 & 1448 & $\mathrm{CJ}$ \\
Phenyl maleic anhydride & 34.29 & 1534 & $\mathrm{CJ}$ \\
Benzophenone* & 36.9 & 1620 & $\mathrm{CJ}$ \\
Pentadecanoic acid & 40.02 & 1867 & $\mathrm{CS}$ \\
Nonadecane** & 40.4 & 1901 & $\mathrm{CS}$ \\
Diphenylsulfone & 40.7 & 1934 & $\mathrm{CS}$ \\
\hline
\end{tabular}

Tentative compound names are shown, which are based on retention time (RT) and ELRI (Experimental linear retention index) values, measured with GC-QTOF-MS. All compounds are significantly more produced by either $C$. jacea (CJ) or $C$. stoebe (CS). Compounds that are produced solely by C. jacea are indicated with '*' and compounds produced solely by $\mathrm{C}$. stoebe with "**.' 
correspond with the attraction to the different plant species. Although they were lower in the rhizosphere of range-expanding Centaurea than in that of native Centaura, no differences were found in the other two plant pairs. The overall very low Helicotylenchus numbers indicate that no - or hardly any reproduction of this species took place in this experiment. While the species did show profound chemical attraction to some of the plant species, we could therefore not properly estimate differences in performance on these different plant species.

Contrary to our hypothesis, but in line with a previous study (Wilschut et al., 2016), the range-expanding Geranium hosted slightly higher numbers of Meloidogyne than the native Geranium, indicating that not all range-expanding plant species are poorer nematode hosts than congeneric natives. Depending on naivety of either the host plant species or the herbivore in a novel plant-herbivore novel interaction, herbivore performance can be found to be strong or weak (Verhoeven et al., 2009). We did not perform experiments using Meloidogyne and Helicotylenchus populations from the original range of the range-expanding plant species, so our data do not allow to draw conclusions on nematode preference and performance of the range-expanding plant species in their native range. However, as gene flow between soil-born nematode populations is expected to be low (Blouin et al., 1999), a certain degree of local adaptation is well possible, so that it may well be that the nematode populations in the new range differ, at least to some extent, from populations in the original range. The use of nematode populations originating from natural areas in the new range and the subsequent culturing on plant species that is phylogenetically unrelated to the examined plant species allowed a phylogenetically unbiased test of the effects of the natural coevolutionary histories between the nematode and plant species on nematode attraction and performance.

We expected that the patterns in nematode attraction, preference and reproduction found in the present study would be caused by differences in root chemistry between native and range-expanding plant species. Indeed, the analyses of volatile compounds revealed that range-expanding C. stoebe produced more unique volatile compounds than native $C$. jacea. These results correspond with a study on aboveground herbivores, in which herbivore performance was also shown to be low on range-expanding and exotic plants with more unique chemistry than their related natives (Macel et al., 2014). In addition to higher numbers of unique compounds, our study also reveals differences in the production levels of several shared volatile compounds between the Centaurea species. Therefore, the nematode repellence and the poor nematode reproduction on the range-expanding C. stoebe, compared to the native C. jacea, might be explained by both the production of higher numbers of unique compounds and by different production levels of shared compounds. Interestingly, novel chemistry of C. stoebe has also been related to the poor performance of aboveground generalist herbivores in North America (Schaffner et al., 2011), where this plant species is invasive. In contrast to range-expanding Centaurea, both range-expanding Rorippa and Geranium produced fewer unique volatiles than their congeneric natives. Differences in volatile profiles were stronger in Geranium than in Rorippa, which was not reflected in the patterns of nematode preference and reproduction. Native Rorippa hosted higher nematode numbers and was more attractive to both nematode species than range-expanding Rorippa, while in Geranium there was no clear nematode preference for either the native or the range-expander, and nematode reproduction levels were higher in the range-expander than in the native. These results suggest that when unique volatile compounds play a role in nematode attraction or distraction, the identity, rather than the number of unique compounds may influence the outcome of plant-nematode interactions. Interestingly, but not unexpectedly, the differences in volatile profiles between all three pairs of congeneric native and range-expanding plant species were smaller than the differences among the three genera. This suggests that while root-feeding nematode species such as Meloidogyne have adapted to plant species with strongly different root chemistries, they may still perform poorly on range-expanding plant species that possess root chemistries slightly deviating from that of the plant species the nematodes are adapted to.

Our volatile analyses revealed, next to many plant volatiles, a large diversity of volatiles emitted by gamma-sterilized soils, which is in line with earlier studies (Schulz-Bohm et al., 2015; Kai et al., 2016). Possibly, the chemical background of the soil caused the differences in nematode attraction between the tests on agar and soil, namely the higher numbers of nematodes moving to the unplanted side on agar. Alternatively, this effect could be caused by a stronger diffusion of root metabolites in the Petri dishes than in the soil-filled Y-tubes, resulting in a more equal distribution of root metabolites throughout the Petri dishes. Based on the differences between the two choice experiments we therefore conclude that choice experiments with root-feeding nematodes should preferably be performed in soil.

The application of GC-QTOF for volatile analysis allowed to obtain the tentative identification of the measured root volatiles. We identified several volatile compounds that were only detected in range-expanding C. stoebe, and therefore could cause the nematode-repelling effect found for this plant species. Root-emitted volatiles are known to play versatile roles in long distance below-ground interactions (Erb et al., 2013; Van Dam and Bouwmeester, 2016) and some of the volatile compounds identified in the present study have been shown to negatively affect nematodes (Piluk et al., 1998). Future studies testing the identified metabolites in different combinations and ratios could reveal which compounds cause the nematode-repelling effect found in C. stoebe. Yet, pin-pointing of the observed effects to a single volatile compound can be complicated, because nematodes might react to a blend of volatiles, rather than to single compounds (Mccormick et al., 2012).

Successful range-expanding plant species have been shown to be better defended against naïve aboveground generalist herbivores than congeneric native plant species (Engelkes et al., 2008), indicating that they may possess superior defense mechanisms compared to related native species in the new range. Such defense mechanisms may especially be effective when they are novel to the natural enemies in the new range. Our results suggest that together with the release of soil enemies from 
the original range (Van Grunsven et al., 2007), the possession of novel chemistry could explain why range-expanding plant species are less negatively affected by soil communities than related native plant species (Van Grunsven et al., 2007; Engelkes et al., 2008). As range-expanding plant species without closely related species in the new range are likely to possess the most unique root chemistries compared to native species present in the community, a phylogenetic approach (as in Strauss et al., 2006) may be considered to forecast which range-expanding plant species have the strongest potential to affect native communities in their novel range (Gilbert and Parker, 2016).

\section{CONCLUSION}

We provide evidence that novel belowground chemistry of the root system of range-expanding plant species may suppress root herbivores in the new range. A range-expander that had the most different root chemistry compared to its related native suppressed root-feeding nematodes more strongly than rangeexpanders with root chemistries that were more comparable to those of related natives. However, our study included six plant species from three genera. Therefore, while our results elucidate the variation in potential impact of range-expanding plant species on native communities in their novel range, further studies are needed in order to be able to generalize these results and predict which range-expanding plant species may have strong impacts on native communities in the future.

\section{REFERENCES}

Bates, D., Maechler, M., Bolker, B., and Walker, S. (2014). Ime4: Linear MixedEffects Models Using Eigen and S4. R Package Version 1.

Berg, M. P., Kiers, E. T., Driessen, G., Van Der Heijden, M., Kooi, B. W., Kuenen, F., et al. (2010). Adapt or disperse: understanding species persistence in a changing world. Glob. Change Biol. 16, 587-598. doi: 10.1111/j.1365-2486.2009.02014.x

Blouin, M. S., Liu, J., and Berry, R. E. (1999). Life cycle variation and the genetic structure of nematode populations. Heredity 83, 253-259. doi: 10.1038/sj.hdy. 6885420

Bongers, T. (1988). De Nematoden van Nederland: Een Identificatietabel voor de in Nederland Aangetroffen Zoetwater-en Bodembewonende Nematoden. Zeist: Koninklijke Nederlandse Natuurhistorische Vereiniging.

Callaway, R. M., and Aschehoug, E. T. (2000). Invasive plants versus their new and old neighbors: a mechanism for exotic invasion. Science 290, 521-523. doi: 10.1126/science.290.5491.521

Callaway, R. M., and Ridenour, W. M. (2004). Novel weapons: invasive success and the evolution of increased competitive ability. Front. Ecol. Environ. 2, 436-443. doi: 10.1890/1540-9295(2004)002[0436:NWISAT]2.0.CO;2

Cappuccino, N., and Arnason, J. T. (2006). Novel chemistry of invasive exotic plants. Biol. Lett. 2, 189-193. doi: 10.1098/rsbl.2005.0433

Cobb, N. (1918). Filter-bed nemas: nematodes of the slow sand filter-beds of American cities (including new genera and species); with notes on hermaphroditism and parthenogensis. Contr. Sci. Nematol. 7, 189-212.

De Frenne, P., Coomes, D. A., De Schrijver, A., Staelens, J., Alexander, J. M., Bernhardt-Römermann, M., et al. (2014). Plant movements and climate warming: intraspecific variation in growth responses to nonlocal soils. New Phytol. 202, 431-441. doi: 10.1111/nph.12672

De Rosario-Martinez, H. (2013). phia: Post-Hoc Interaction Analysis. R Package Version $0.1-3$.

Dostálek, T., Münzbergová, Z., Kladivová, A., and Macel, M. (2015). Plant-soil feedback in native vs. invasive populations of a range expanding plant. Plant Soil 399, 209-220. doi: 10.1007/s11104-015-2688-x

\section{AUTHOR CONTRIBUTIONS}

All authors contributed to the design of the study. Greenhouse experiments were performed by JS and RW. The volatile experiment was performed by PG and JS. Data analyses were performed by RW, PG, and JS. The manuscript was written by RW with the help of all other authors.

\section{FUNDING}

This study was supported by the European Research Council [ERC advanced grant ERCAdv 26055290 (SPECIALS) to WP] and a CAPES PDSE grant to JS.

\section{ACKNOWLEDGMENTS}

We thank Hans Zweers for performing GC-QTOF analyses and Carolin Weser for help with seed germination. This is publication 6379 of the Netherlands Institute of Ecology (NIOO-KNAW).

\section{SUPPLEMENTARY MATERIAL}

The Supplementary Material for this article can be found online at: https://www.frontiersin.org/articles/10.3389/fpls.2017.01861/ full\#supplementary-material

Engelkes, T., Morrien, E., Verhoeven, K. J. F., Bezemer, T. M., Biere, A., Harvey, J. A., et al. (2008). Successful range-expanding plants experience less aboveground and below-ground enemy impact. Nature 456, 946-948. doi: 10.1038/ nature 07474

Erb, M., Huber, M., Robert, C. A. M., Ferrieri, A. P., Machado, R. A. R., and Arce, C. C. M. (2013). "Chapter two - the role of plant primary and secondary metabolites in root-herbivore behaviour, nutrition and physiology," in Advances in Insect Physiology, eds I. H. Scott, N. Johnson, and C. J. T. Ted (Cambridge, MA: Academic Press), 53-95.

Floron (2017). Verspreidingsatlas Planten. Available at: http://www. verspreidingsatlas.nl/planten

Gilbert, G. S., and Parker, I. M. (2016). The evolutionary ecology of plant disease: a phylogenetic perspective. Annu. Rev. Phytopathol. 54, 549-578. doi: 10.1146/ annurev-phyto-102313-045959

Holt, R. D. (1977). Predation, apparent competition, and the structure of prey communities. Theor. Popul. Biol. 12, 197-229. doi: 10.1016/0040-5809(77) 90042-9

Kai, M., Effmert, U., and Piechulla, B. (2016). Bacterial-plant-interactions: approaches to unravel the biological function of bacterial volatiles in the rhizosphere. Front. Microbiol. 7:108. doi: 10.3389/fmicb.2016.00108

Kuznetsova, A., Brockhoff, P. B., and Christensen, R. H. B. (2015). Package 'ImerTest'. R Package Version 2.

Lavergne, S., Mouquet, N., Thuiller, W., and Ronce, O. (2010). Biodiversity and climate change: integrating evolutionary and ecological responses of species and communities. Annu. Rev. Ecol. Evol. Syst. 41, 321-350. doi: 10.1146/annurevecolsys-102209- 144628

Le Roux, P. C., and Mcgeoch, M. A. (2008). Rapid range expansion and community reorganization in response to warming. Glob. Change Biol. 14, 2950-2962. doi: 10.1111/j.1365-2486.2008.01687.x

Macel, M., De Vos, R. C. H., Jansen, J. J., Van Der Putten, W. H., and Van Dam, N. M. (2014). Novel chemistry of invasive plants: exotic species have more unique metabolomic profiles than native congeners. Ecol. Evol. 4, 2777-2786. doi: $10.1002 /$ ece 3.1132 
Mccormick, A. C., Unsicker, S. B., and Gershenzon, J. (2012). The specificity of herbivore-induced plant volatiles in attracting herbivore enemies. Trends Plant Sci. 17, 303-310. doi: 10.1016/j.tplants.2012.03.012

Morriën, E., Duyts, H., and Van Der Putten, W. H. (2012). Effects of native and exotic range-expanding plant species on taxonomic and functional composition of nematodes in the soil food web. Oikos 121, 181-190. doi: 10.1111/j.16000706.2011.19773.x

Morriën, E., and Van Der Putten, W. H. (2013). Soil microbial community structure of range-expanding plant species differs from co-occurring natives. J. Ecol. 101, 1093-1102. doi: 10.1111/1365-2745.12117

Oostenbrink, M. (1960). "Estimating nematode populations by some elected methods," in Nematology, eds J. N. Sasser and W. R. Jenkins (Chapel Hill, NC: University of North Carolina Press), 85-102.

Orrock, J. L., Witter, M. S., and Reichman, O. J. (2008). Apparent competition with an exotic plant reduces native plant establishment. Ecology 89, 1168-1174. doi: 10.1890/07-0223.1

Parmesan, C. (2006). Ecological and evolutionary responses to recent climate change. Annu. Rev. Ecol. Evol. Syst. 37, 637-669. doi: 10.1146/annurev.ecolsys. 37.091305.110100

Piluk, J., Hartel, P. G., and Hanies, B. (1998). "Production of carbon disulfide (CS2) from L-djenkolic acid in the roots of Mimosa pudica L," in Root Demographics and Their Efficiencies in Sustainable Agriculture, Grasslands and Forest Ecosystems, ed. J. E. Box Jr. (Berlin: Springer), 127-137.

Piskiewicz, A. M., De Milliano, M. J. K., Duyts, H., and Van Der Putten, W. H. (2009). Plant ectoparasitic nematodes prefer roots without their microbial enemies. Plant Soil 316, 277-284. doi: 10.1007/s11104-008-9779-x

Pluskal, T., Castillo, S., Villar-Briones, A., and Orešiè, M. (2010). MZmine 2: modular framework for processing, visualizing, and analyzing mass spectrometry-based molecular profile data. BMC Bioinformatics 11:395. doi: 10.1186/1471-2105-11-395

R Core Development Team (2012). R: A Language and Environment for Statistical Computing. Vienna: R Foundation for Statistical Computing.

Rasmann, S., Köllner, T. G., Degenhardt, J., Hiltpold, I., Toepfer, S., Kuhlmann, U., et al. (2005). Recruitment of entomopathogenic nematodes by insect-damaged maize roots. Nature 434, 732-737. doi: 10.1038/nature03451

Rolfe, R. N., Barrett, J., and Perry, R. N. (2000). Analysis of chemosensory responses of second stage juveniles of Globodera rostochiensis using electrophysiological techniques. Nematology 2, 523-533. doi: 10.1163/156854100509448

Schaffner, U., Ridenour, W. M., Wolf, V. C., Bassett, T., Mueller, C., MuellerSchaerer, H., et al. (2011). Plant invasions, generalist herbivores, and novel defense weapons. Ecology 92, 829-835. doi: 10.1890/10-1230.1

Schulz-Bohm, K., Zweers, H., De Boer, W., and Garbeva, P. (2015). A fragrant neighborhood: volatile mediated bacterial interactions in soil. Front. Microbiol. 6:1212. doi: $10.3389 /$ fmicb. 2015.01212

Stein, S. E. (1999). An integrated method for spectrum extraction and compound identification from gas chromatography/mass spectrometry data. J. Am. Soc. Mass Spectrom. 10, 770-781. doi: 10.1016/S1044-0305(99) 00047-1

Strauss, S. Y., Webb, C. O., and Salamin, N. (2006). Exotic taxa less related to native species are more invasive. Proc. Natl. Acad. Sci. U.S.A. 103, 5841-5845. doi: $10.1073 /$ pnas. 0508073103
Turlings, T. C. J., Hiltpold, I., and Rasmann, S. (2012). The importance of rootproduced volatiles as foraging cues for entomopathogenic nematodes. Plant Soil 358, 47-56. doi: 10.1007/s11104-012-1295-3

Van Dam, N. M., and Bouwmeester, H. J. (2016). Metabolomics in the rhizosphere: tapping into belowground chemical communication. Trends Plant Sci. 21, 256-265. doi: 10.1016/j.tplants.2016.01.008

Van Der Putten, W. H. (2012). Climate change, aboveground-belowground interactions, and species' range shifts. Annu. Rev. Ecol. Evol. Syst. 43, 365-383. doi: 10.1146/annurev-ecolsys-110411-160423

Van Grunsven, R. H. A., Van Der Putten, W. H., Bezemer, T. M., Tamis, W. L. M., Berendse, F., and Veenendaal, E. M. (2007). Reduced plant-soil feedback of plant species expanding their range as compared to natives. J. Ecol. 95, 1050-1057. doi: 10.1007/s00442-009-1526-3

Van Tol, R., Van Der Sommen, A. T. C., Boff, M. I. C., Van Bezooijen, J., Sabelis, M. W., and Smits, P. H. (2001). Plants protect their roots by alerting the enemies of grubs. Ecol. Lett. 4, 292-294. doi: 10.1046/j.1461-0248.2001. 00227.x

Venables, W. N., and Ripley, B. D. (2013). Modern Applied Statistics with S-PLUS. Berlin: Springer Science \& Business Media.

Verhoeven, K. J. F., Biere, A., Harvey, J. A., and Van Der Putten, W. H. (2009). Plant invaders and their novel natural enemies: Who is naive? Ecol. Lett. 12, 107-117. doi: 10.1111/j.1461-0248.2008.01248.x

Viketoft, M., and Van Der Putten, W. H. (2014). Top-down control of root-feeding nematodes in range-expanding and congeneric native plant species. Basic Appl. Ecol. 16, 260-268. doi: 10.1016/j.baae.2014.12.006

Walther, G. R., Post, E., Convey, P., Menzel, A., Parmesan, C., Beebee, T. J. C., et al. (2002). Ecological responses to recent climate change. Nature 416, 389-395. doi: $10.1038 / 416389$ a

Wilschut, R., Geisen, S., Ten Hooven, F., and Van Der Putten, W. (2016). Interspecific differences in nematode control between range-expanding plant species and their congeneric natives. Soil Biol. Biochem. 100, 233-241. doi: 10.1016/j.soilbio.2016.06.025

Xia, J., Sinelnikov, I. V., Han, B., and Wishart, D. S. (2015). MetaboAnalyst 3.0-making metabolomics more meaningful. Nucleic Acids Res. 43, W251-W257. doi: 10.1093/nar/gkv380

Zheng, Y. L., Feng, Y. L., Zhang, L. K., Callaway, R. M., Valiente-Banuet, A., Luo, D. Q., et al. (2015). Integrating novel chemical weapons and evolutionarily increased competitive ability in success of a tropical invader. New Phytol. 205, 1350-1359. doi: 10.1111/nph.13135

Conflict of Interest Statement: The authors declare that the research was conducted in the absence of any commercial or financial relationships that could be construed as a potential conflict of interest.

Copyright (c) 2017 Wilschut, Silva, Garbeva and van der Putten. This is an openaccess article distributed under the terms of the Creative Commons Attribution License (CC BY). The use, distribution or reproduction in other forums is permitted, provided the original author(s) or licensor are credited and that the original publication in this journal is cited, in accordance with accepted academic practice. No use, distribution or reproduction is permitted which does not comply with these terms. 